\title{
MASSA ESPECÍFICA APARENTE E REAL E POROSIDADE DE GRÃOS DE CAFÉ EM FUNÇÃO DO TEOR DE UMIDADE
}

\author{
Sandra Maria Couto ${ }^{1}$, Anderson Chagas Magalhães ${ }^{2}$, Daniel Marçal de Queiroz ${ }^{1}$ \\ e Itaciane Toledo Bastos ${ }^{3}$
}

\begin{abstract}
RESUMO
Esta pesquisa foi desenvolvida com o objetivo de se obter valores para algumas características físicas do café, necessárias ao desenvolvimento de unidades de separação aerodinâmicas e ao dimensionamento de secadores e silos. Investigou-se o efeito do teor de umidade nos valores da massa específica real e aparente, e nos da porosidade de grão de café das variedades Catuaí e Timor. Os grãos, colhidos em dois estádios de maturação (verde e cereja) foram submetidos a um processo de secagem em terreiro de cimento; trabalhou-se com dois lotes de café da variedade Catuaí, colhidos em épocas diferentes e a época de colheita não produziu alterações relevantes nos valores das massas específicas real e aparente; por outro lado, a massa específica real do café aumenta com acréscimos na umidade do grão, enquanto a massa específica aparente decresce. Os valores para essas massas são menores que aqueles para a maioria dos grãos agrícolas; entretanto, a porosidade de ambas encontrase na mesma faixa de valores.
\end{abstract}

Palavras-chave: massa específica real, massa específica aparente, porosidade, Coffee arabica L.

\section{UNITY AND BULK DENSITIES AND POROSITY OF COFFEE AS AFFECTED BY MOISTURE CONTENT}

\begin{abstract}
This research presents values for some physical characteristics of coffee necessary for development of aerodynamic separation units and for design of driers and silos. The effect of moisture content on the values of unity and bulk density and porosity of coffee varieties Catuaí and Timor, was investigated. The coffee was harvested in two stages of maturation (green and cherry). The grains from cultivar Catuaí were harvested in two different periods. The harvesting period did not cause differences on the values of the densities. The behaviors of unity and bulk densities of coffee were different from those observed for most of the agricultural grains. The unity density of coffee increased with increases in moisture content, whereas the bulk density decreased. The unity and bulk density values for coffee are lower than those for others grains, but the values for porosity were found to be in the same range.
\end{abstract}

Key words: unit density, bulk density, porosity, Coffee arabica $\mathrm{L}$

\footnotetext{
${ }^{1}$ Professor, PhD, Departamento de Engenharia Agrícola, Universidade Federal de Viçosa, CEP 36570 Viçosa, MG, Brasil. E-mail: scouto@mail.ufv.br

${ }^{2}$ Estudante de Pós-Graduação, Departamento de Engenharia Agrícola, Universidade Federal de Viçosa

${ }^{3}$ Estudante de Graduação, Departamento de Engenharia Agrícola, Universidade Federal de Viçosa
} 


\section{INTRODUÇÃO}

A separação rápida e adequada dos diversos materiais provenientes da colheita do café (folha, pau, pedra, terra, frutos: verdes, maduros, passas, secos etc.) é uma etapa do seu processamento, que deve ser executada de maneira eficiente e econômica para se obter um produto final homogêneo, segundo a sua qualidade. Neste sentido, processos aerodinâmicos, nos quais os grãos são submetidos a um fluxo de ar, podem propiciar separação do produto, de acordo com variações de tamanho ou de materiais indesejáveis encontrados em um lote.

Segundo Srivastava et al. (1993) o tamanho e a massa são as características mais importantes relacionadas à limpeza de um produto, sendo o fluxo de ar intimamente influenciado pela massa. Este processo baseia-se em possíveis diferenças nos valores entre as massas específicas dos grãos, nos diferentes estádios de maturação, e dos materiais estranhos; se as diferenças forem significativas, haverá a possibilidade real de se executar tal separação.

Para a boa qualidade do café, este precisa passar por cuidados especiais nos processos de secagem e armazenagem, além dos aspectos agronômicos e de colheita, em que a massa específica e a porosidade da massa de grãos são parâmetros relevantes, tanto para a comercialização do produto quanto para um dimensionamento eficiente de silos, secadores, depósitos, sistemas de transporte e projetos de máquinas beneficiadoras.

A massa específica aparente de grãos agrícolas cresce, geralmente, com a diminuição do teor de umidade do produto. $\mathrm{O}$ crescimento depende da percentagem de grãos danificados, do teor de umidade inicial, da temperatura alcançada durante a secagem, do teor de umidade final e da variedade do grão (Brooker et al., 1992).

Nelson (1980) investigou o efeito do teor de umidade de grãos de trigo (3 a $24 \%$ b.u.) e de milho (10 a $35 \%$ b.u.) nos valores das massas específicas real e aparente; para o trigo, essas massas específicas aumentaram ligeiramente com o aumento da umidade do grão (de 3 a $8 \%$ b.u.) e, a seguir, diminuíram de maneira marcante e contínua com acréscimo no teor de umidade. As massas específicas real e aparente de grãos de milho diminuíram de forma contínua com acréscimos na umidade do grão, até $30 \%$ b.u.; a seguir, ocorreu aumento acentuado da massa específica real com acréscimo no teor de umidade, enquanto a massa específica aparente continuava a decrescer, sem tendência a aumentar.

Hall (1972) secando grãos de milho (de 25 a $29 \%$ até $15,5 \%$ b.u.) a diferentes temperaturas, observou que, para grãos colhidos e debulhados manualmente, a massa especíica aparente aumentava com decréscimo no teor de umidade do produto e concluiu que, ao final da secagem, a massa específica aparente de uma amostra crescia a medida em que se diminuía a temperatura usada neste processo. Durante as secagens, a temperaturas mais altas, foram observadas, também, reduções de massa específica aparente com diminuição no teor de umidade do produto, principalmente a teores abaixo de $18 \%$ b.u.

Hall et al. (1972) investigaram o efeito da redução do teor de umidade de grãos de milho nos valores da massa específica real e porosidade, durante a secagem deste produto. Nos dois lotes, inicialmente nas faixas de $52-61 \%$ b.s. e de 32 - $35 \%$ b.s., que tiveram suas umidades reduzidas para valores entre
$6-10 \%$ b.s., a massa específica real aumentou com reduções no teor de umidade, mas a porosidade diminuiu com decréscimo na umidade do grão, até um valor mínimo (entre 17 a $24 \%$ b.s.) e, a seguir, cresceu com decréscimo no teor de umidade.

Brusewitz (1975) detectou que, para uma faixa de umidade de 15 a $45 \%$ b.u., os valores da massa específica real, de diversos grãos reumedecidos investigados, decresceram com o aumento no teor de umidade do produto, porém a massa específica aparente diminuiu com acréscimo no teor de umidade, até certo valor e, a seguir, cresceu com o aumento no teor de umidade. Dos grãos testados, os de soja foram os únicos que tiveram suas massas específicas aparentes crescentes com decréscimo no teor de umidade, durante o intervalo testado.

$\mathrm{Na}$ determinação da massa específica aparente utiliza-se, geralmente, uma balança de peso hectolítrico ou um picnômetro. A massa específica real dos grãos agrícolas pode ser determinada pelo método do deslocamento de líquidos (Moreira et al.,1985). Para a utilização deste método, que requer apenas equipamentos comuns de laboratório, é aconselhável o uso de um líquido com característica de penetração mínima nos poros do grão. Em um estudo comparativo da eficiência de líquidos complementares de volume na determinação da massa específica real de grãos agrícolas, Moreira et al. (1985) concluíram que o óleo de soja pode ser usado como substituto do tolueno e que a utilização de água destilada é totalmente inviável; outro método de obtenção da massa específica bastante usado é o do deslocamento de ar, que requer aparelhagem especial (picnômetro e acessórios); neste caso, cuidados devem ser tomados quanto a problemas relacionados com a variação de temperatura e o vazamento de ar no picnômetro, durante as determinações.

Apesar do café ser uma cultura antiga, valores para massas específicas aparente e real e para porosidade deste produto são limitados e dispersos. Visando obter dados que possam ser utilizados no desenvolvimento de sistemas de separação durante os processos de colheita e pós-colheita do café, no dimensionamento de secadores e silos, este trabalho teve por objetivo a investigação do efeito do teor de umidade nas massas específicas real e aparente e na porosidade de grãos de café.

\section{MATERIAL E MÉTODOS}

O trabalho foi conduzido no Laboratório de Armazenamento e Processamento de Produtos Agrícolas do Departamento de Engenharia Agrícola da Universidade Federal de Viçosa.

Foram utilizados grãos de café das variedades Catuaí e Híbrido Timor, provenientes de uma região de Viçosa, MG, localizada a uma latitude de $20^{\circ} 52^{\prime}$ ' $04^{\prime \prime}$ oeste, com altitude de 657 m. Os grãos da variedade Catuaí foram colhidos em épocas diferentes e, neste trabalho, são denominados lotes 1 e 2.

Grãos de café de cada uma das variedades, colhidos no sistema convencional na forma de derriça no pano, foram submetidos a um processo de classificação e separados nas categorias verde e cereja; a seguir, os grãos das duas categorias foram secos, em terreiro de cimento, para a obtenção de amostras a cinco teores de umidade diferentes. Os teores de umidade dos grãos foram determinados pelo método da estufa a $105^{\circ} \mathrm{C}$ por $96 \mathrm{~h}$. 
A massa específica real dos grãos de café foi determinada usando-se a metodologia de complementação de volume (Moreira et al., 1985) e o tolueno como líquido. Como esta metodologia foi desenvolvida para grãos de pequenas dimensões, algumas adaptações tiveram de ser realizadas.

A massa específica real de um produto é obtida pela equação:

$$
\rho=\frac{m}{v}
$$

em que é a massa específica $\left(\mathrm{g} \cdot \mathrm{cm}^{-3}\right)$, m é a massa de grãos (g) e v é volume dos grãos $\left(\mathrm{cm}^{3}\right)$.

Na metodologia desenvolvida por Moreira et al. (1985) são utilizados, para determinação da massa específica real com, no mínimo, duas casas decimais, uma balança semianalítica $\left( \pm 10^{-3} \mathrm{~g}\right)$ para a determinação da massa, e balões volumétricos de capacidade de $10 \mathrm{~mL}( \pm 0,04 \mathrm{~mL})$ que, em geral, comportam de 20 a 100 grãos, conforme o tipo do produto sendo testado. A utilização desses balões volumétricos para grãos de café é inviável devido ao pequeno diâmetro do seu gargalo.

Sendo o café um produto novo, em termos de sua caracterização física, resolveu-se realizar uma análise das incertezas envolvidas na determinação da massa específica real, ao se usar os balões volumétricos e provetas de $50 \mathrm{~mL}( \pm 0,5 \mathrm{~mL})$ disponíveis no laboratório e viáveis de utilização para grãos de café.

A incerteza nos valores da massa específica, devido à instrumentação usada na sua determinação, foi determinada por:

$$
|d \rho|= \pm \frac{1}{v} \sqrt{d m^{2}+\rho^{2} d v^{2}}
$$

$\mathrm{ou}$

$$
= \pm \frac{1}{v} \sqrt{(0,001)^{2}+\rho^{2}(0,04 \text { ou } 0,5)^{2}}
$$

em que $d m$ é a incerteza na determinação da massa e dv é a incerteza na determinação do volume.

Os resultados desta análise de incertezas foram usados para definir se a proveta seria adequada para a obtenção da massa específica real do café e o número de grãos a serem utilizados em cada determinação.

Para a determinação da massa específica aparente das amostras de grãos de café, utilizou-se uma balança de peso hectolítrico, com capacidade para um litro, da marca Dallemole.

As determinações das massas específicas real e aparente foram realizadas em três repetições.

Conhecendo-se as massas específicas real $\left(\rho_{g}\right)$ e aparente $\left(\rho_{g}\right)$ a porosidade $(\mathrm{P})$ de um volume de grãos foi calculada pela equação:

$$
P=1-\frac{\rho}{\rho_{g}}
$$

\section{RESULTADOS E DISCUSSÃO}

\section{Considerações gerais}

A Tabela 1 apresenta o resumo geral dos valores médios da massa específica real e aparente, e da porosidade, determinados para amostras de café de diferentes variedades, teores de umidade e graus de maturação. As médias e desvios-padrão, apresentados nessa Tabela, são provenientes de três determinações

Os cinco níveis de umidade dos grãos de cada variedade usados nas determinações, Tabela 1, diferem. Visando-se a uma comparação dos valores dessas grandezas entre as duas variedades ajustaram-se, aos dados experimentais (regressão) polinômios de segundo grau, cujas equações são representadas, neste trabalho, na seguinte forma genérica: $A+B$ U + C U2 em que $\mathrm{A}, \mathrm{B}$ e $\mathrm{C}$ são os coeficientes das regressões e $\mathrm{U}$ simboliza o teor de umidade.

Os coeficientes das equações ajustadas, acompanhados dos

\begin{tabular}{|c|c|c|c|c|c|c|c|c|c|c|c|c|c|c|}
\hline \multirow{4}{*}{$\begin{array}{c}\text { Variedade } \\
\text { e Lote }\end{array}$} & \multicolumn{7}{|c|}{ Verde } & \multicolumn{7}{|c|}{ Cereja } \\
\hline & \multirow{3}{*}{$\begin{array}{l}\text { Umidade } \\
\text { (\% b.u.) }\end{array}$} & \multicolumn{4}{|c|}{ Massa específica } & \multicolumn{2}{|c|}{ Porosidade $(\%)$} & \multirow{3}{*}{$\begin{array}{l}\text { Umidade } \\
\text { (\% b.u.) }\end{array}$} & \multicolumn{4}{|c|}{ Massa específica } & \multicolumn{2}{|c|}{ Porosidade $(\%)$} \\
\hline & & \multicolumn{2}{|c|}{$\begin{array}{c}\text { Real } \\
\left(\mathrm{g} \mathrm{cm}^{-3}\right)\end{array}$} & \multicolumn{2}{|c|}{$\begin{array}{c}\text { Aparente } \\
\left(\mathrm{kg} \mathrm{m}^{-3}\right)\end{array}$} & \multirow[b]{2}{*}{ Média } & \multirow[b]{2}{*}{$\begin{array}{l}\text { Desvio } \\
\text { padrão }\end{array}$} & & \multicolumn{2}{|c|}{$\begin{array}{c}\text { Real } \\
\left(\mathrm{g} \mathrm{cm}^{-3}\right)\end{array}$} & \multicolumn{2}{|c|}{$\begin{array}{c}\text { Aparente } \\
\left(\mathrm{kg} \mathrm{m}^{-3}\right)\end{array}$} & \multirow[b]{2}{*}{ Média } & \multirow[b]{2}{*}{$\begin{array}{l}\text { Desvio- } \\
\text { padrão }\end{array}$} \\
\hline & & Média & $\begin{array}{l}\text { Desvio- } \\
\text { padrão }\end{array}$ & Média & $\begin{array}{l}\text { Desvio- } \\
\text { padrão }\end{array}$ & & & & Média & $\begin{array}{c}\text { Desvio- } \\
\text { padrão }\end{array}$ & Média & $\begin{array}{l}\text { Desvio- } \\
\text { padrão }\end{array}$ & & \\
\hline \multirow[t]{5}{*}{ Catuaí Lote 1} & 67,9 & 1,072 & 0,015 & 537,6 & 3 & 49,8 & 0,2 & 67,5 & 1,097 & 0,010 & 606,6 & 13 & 44,7 & 1,2 \\
\hline & 61,9 & 1,048 & 0,005 & 533,8 & 10 & 49,0 & 1,0 & 61,4 & 1,04 & 0,052 & 560,7 & 6 & 46,1 & 0,5 \\
\hline & 51,1 & 1,001 & 0,054 & 490,9 & 2 & 51,0 & 0,2 & 46,9 & 0,997 & 0,006 & 500,1 & 3 & 49,9 & 0,3 \\
\hline & 30,3 & 0,864 & 0,018 & 448,6 & 3 & 48,1 & 0,4 & 29,3 & 0,892 & 0,011 & 459,1 & 5 & 48,5 & 0,5 \\
\hline & 17,2 & 0,681 & 0,014 & 391,3 & 4 & 42,5 & 0,5 & 18,7 & 0,782 & 0,035 & 414,9 & 4 & 47,0 & 0,5 \\
\hline \multirow[t]{5}{*}{ Catuaí Lote 2} & 68,0 & 1,068 & 0,032 & 555,2 & 4 & 48,0 & 0,3 & 70,4 & 1,124 & 0,002 & 587,0 & 1 & 47,8 & 0,1 \\
\hline & 61,0 & 1,059 & 0,018 & 540,3 & 2 & 49,0 & 0,2 & 57,9 & 0,996 & 0,040 & 524,5 & 4 & 47,3 & 0,4 \\
\hline & 50,7 & 0,995 & 0,004 & 527,5 & 5 & 47,0 & 0,5 & 40,4 & 0,914 & 0,026 & 478,7 & 3 & 47,6 & 0,3 \\
\hline & 35,9 & 0,867 & 0,014 & 457,7 & 1 & 47,2 & 0,0 & 28,8 & 0,829 & 0,003 & 414,4 & 1 & 50,0 & 0,1 \\
\hline & 12,7 & 0,640 & 0,034 & 391,5 & 5 & 38,8 & 0,8 & 13,3 & 0,729 & 0,02 & 393,6 & 5 & 46,0 & 0,6 \\
\hline \multirow[t]{5}{*}{ Timor } & 65,2 & 0,990 & 0,023 & 548,4 & 3 & 44,6 & 0,2 & 62,6 & 1,020 & 0,014 & 555,3 & 9 & 45,5 & 0,9 \\
\hline & 55,1 & 0,933 & 0,034 & 480,8 & 3 & 48,5 & 0,4 & 53,0 & 0,938 & 0,014 & 515,4 & 1 & 45,0 & 0,1 \\
\hline & 41,5 & 0,855 & 0,006 & 401,5 & 3 & 53,0 & 0,3 & 40,0 & 0,903 & 0,017 & 473,3 & 7 & 47,6 & 0,8 \\
\hline & 18,5 & 0,720 & 0,024 & 343,4 & 1 & 52,3 & 0,1 & 22,9 & 0,814 & 0,071 & 406,8 & 3 & 50,7 & 0,4 \\
\hline & 9,5 & 0,565 & 0,102 & 341,1 & 10 & 39,6 & 1,7 & 11,1 & 0,704 & 0,049 & 400,2 & 6 & 43,2 & 0,9 \\
\hline
\end{tabular}
coeficientes de determinação $\left(\mathrm{R}^{2}\right)$ encontram-se na Tabela 2.

Tabela 1. Massa específica, real e aparente, e porosidade, para amostras de café de diferentes variedades a diferentes teores de umidade 
Tabela 2. Coeficientes das equações quadráticas $\left(A+B U+C U^{2}\right)$ ajustadas para, através delas, descrever o comportamento da massa específica real e aparente, e porosidade de grãos de café em função do teor de umidade (U)

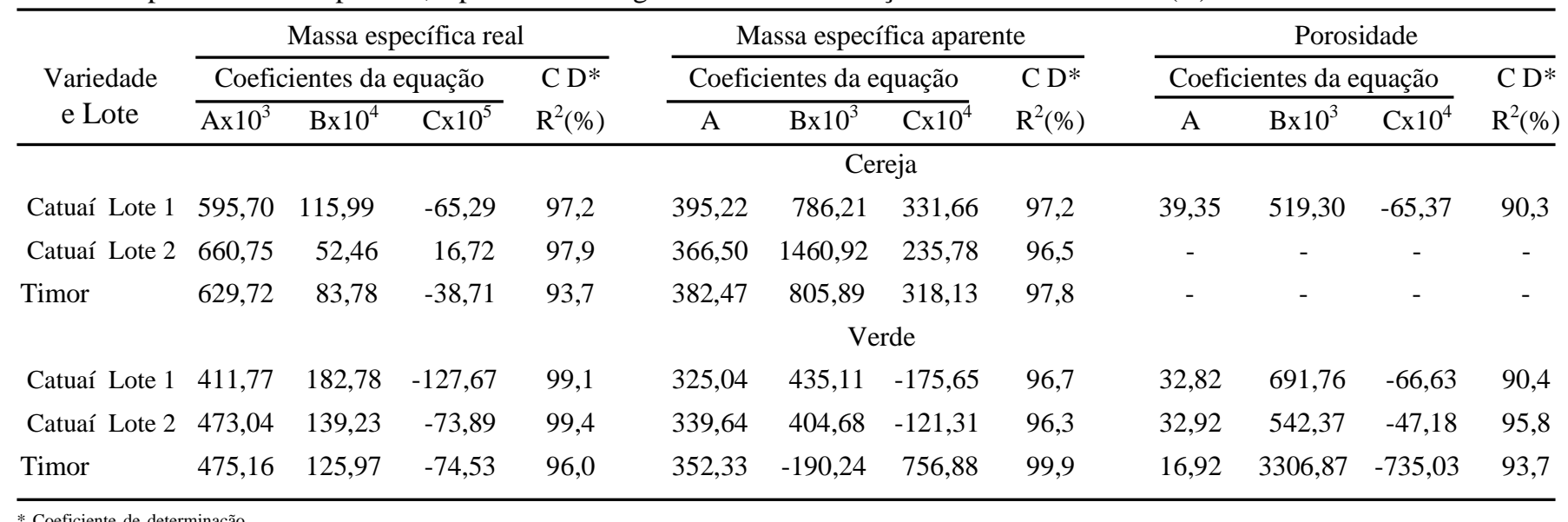

\section{Massa específica real}

Para a determinação das incertezas envolvidas na massa específica real, utilizando-se a Eq (2) é necessário a obtenção de faixas de valores para as massas específicas e para os volumes unitários de grãos de café. Foram realizados, então, alguns testes preliminares, que resultaram em valores para massa específica real de grãos de café, variando entre 0,7 e $1,3 \mathrm{~g} \mathrm{~cm}^{-3} \mathrm{e}$, para o volume unitário dos grãos, entre 0,7 e $1,5 \mathrm{~cm}^{-3}$.

$\mathrm{Na}$ Tabela 3 encontram-se os valores simulados para as incertezas, ao serem usados na Eq (3): (a) os valores extremos da massa específica e volume do grão; (b) diferentes números de grãos em cada determinação; e (c) os dois tipos de frasco.

Evidentemente, os maiores valores de massa específica serão acompanhados das maiores incertezas, que podem ser atenuadas ao se usar um volume maior de grãos (aumentando-se o número de grãos em cada determinação).

Além desse tipo de incerteza existe, ainda, aquela devida à variação inerente entre grãos, impossível de ser alterada. Para minimizar as incertezas (instrumental e de metodologia) na determinação da massa específica real, utilizaram-se provetas de 50,0 mL ( 0,5 mL) e 20 grãos em cada determinação. Os valores determinados para as massas específicas reais, média e desviopadrão, são apresentados na Tabela 1. Observa-se, que existe, para cada variedade, tendência da massa específica diminuir com o decréscimo no teor de umidade do produto, indicando que, ao se reduzir a umidade do grão, a sua massa é reduzida mais rapidamente que o volume. Os valores da massa específica variaram de $0,565 \mathrm{~g} \mathrm{~cm}^{-3}$ (Timor verde, $9,5 \%$ b.u.) até $1,124 \mathrm{~g} \mathrm{~cm}^{-3}$ (Catuaí cereja, lote $2,70,4 \%$ b.u.).

Curvas das equações ajustadas, em que os coeficientes das respectivas equações encontram-se na Tabela 2, e os valores médios da massa específica real de grãos de café das variedades Catuaí e Timor, usando-se 20 grãos em cada determinação, podem ser visualizados na Figura 1, para grãos verdes e cereja.

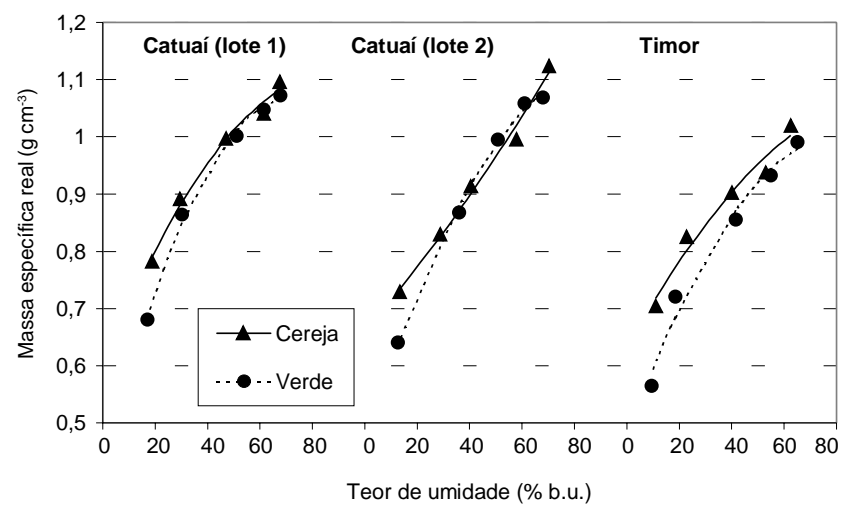

Figura 1. Massa específica real de grãos individuais de café das variedades Catuaí e Timor, classificados como cereja e verde, em função do teor de umidade; curvas ajustadas e valores experimentais

Nota-se, na Figura 1, que existe diferença entre o comportamento da massa específica para grãos classificados,

Tabela 3. Incertezas devido à aparelhagem e metodologia usadas na determinação da massa específica real de grãos de café

\begin{tabular}{|c|c|c|c|c|c|c|c|c|c|c|}
\hline \multirow{4}{*}{$\begin{array}{c}\rho \\
\left(\mathrm{g} \mathrm{cm}^{-3}\right)\end{array}$} & \multicolumn{10}{|c|}{ Número de grãos } \\
\hline & \multicolumn{2}{|c|}{1} & \multicolumn{2}{|c|}{5} & \multicolumn{2}{|c|}{10} & \multicolumn{2}{|c|}{15} & \multicolumn{2}{|c|}{20} \\
\hline & \multicolumn{10}{|c|}{ Volume dos grãos $\left(\mathrm{cm}^{3}\right)$} \\
\hline & 0,7 & 1,5 & 3,5 & 7,5 & 7 & 15 & 10,5 & 22,5 & 14 & 30 \\
\hline & \multicolumn{10}{|c|}{ Balão Volumétrico de 10,00 mL ( $\pm 0,04 \mathrm{ml})$} \\
\hline 0,7 & 0,04 & 0,02 & 0,008 & 0,004 & 0,004 & 0,002 & 0,003 & 0,001 & 0,002 & 0,001 \\
\hline 1,3 & 0,07 & 0,03 & 0,01 & 0,007 & 0,007 & 0,003 & 0,005 & 0,002 & 0,004 & 0,002 \\
\hline \multicolumn{11}{|c|}{ Proveta de $50,0 \mathrm{~mL}( \pm 0,5 \mathrm{ml})$} \\
\hline 0,7 & 0,5 & 0,2 & 0,1 & 0,05 & 0,05 & 0,02 & 0,03 & 0,02 & 0,03 & 0,01 \\
\hline 1,3 & 0,9 & 0,4 & 0,2 & 0,09 & 0,09 & 0,04 & 0,06 & 0,03 & 0,05 & 0,02 \\
\hline
\end{tabular}


inicialmente, como cereja e verde. Percebe-se, também, maior distanciamento entre as massas específicas para grãos da variedade Timor e para a variedade Catuaí, lotes 1 e 2 , o distanciamento entre as massas específicas torna-se menor para grãos com teores de umidade mais altos. Se as equações ajustadas forem utilizadas para teores de umidade equivalentes, verificar-se-á que, em média, as massas específicas de grãos inicialmente classificados como cereja são 1,05, 1,02 e 1,08 vezes superiores às massas dos grãos verdes, para as variedades Catuaí, lotes 1 e 2, e Timor, respectivamente.

A Figura 2 apresenta valores provenientes das equações ajustadas, para as massas específicas dos grãos das duas variedades de café, classificados inicialmente como cereja e verde, para um intervalo comum de umidade ( 18,6 a $62,6 \%$ b.u.). Pode-se observar que os maiores valores são para grãos cereja da variedade Catuaí (lote 1). Estes valores são, em média, para todos os teores de umidade, $11 \%$ superiores àqueles para a variedade Timor, verde, que apresentam os menores valores de massa específica. Para a variedade Catuaí, as razões entre os valores de massa específica para grãos do lote 1 e do lote 2 foram, em média, iguais a 1,02 e 1,05, para grãos de início classificados como verde e cereja, respectivamente; portanto, as massas específicas dos lotes 1 e 2 da variedade Catuaí são bastante próximas, indicando não ter havido alterações relevantes no produto, devido à época de colheita (Figura 1).

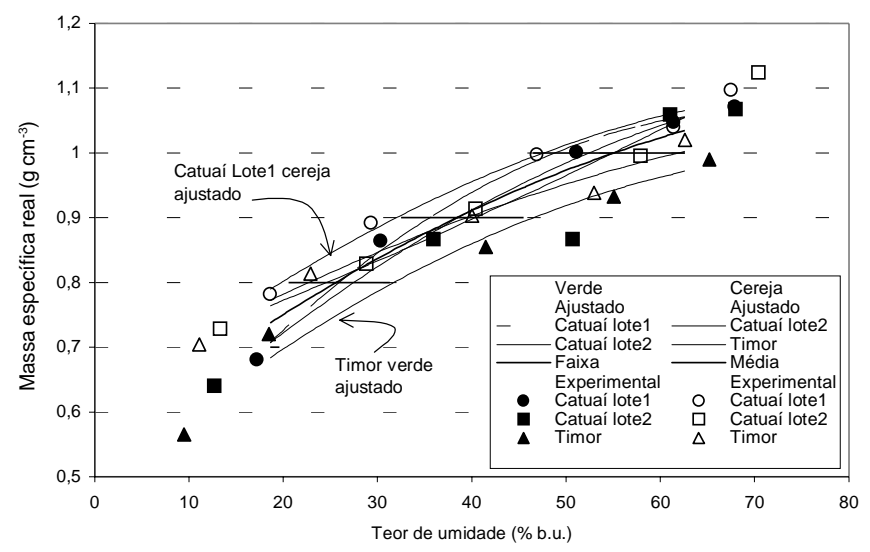

Figura 2. Massa específica real, proveniente das equações ajustadas, de grãos de café das variedades Catuaí e Timor, inicialmente classificados como cereja e verde, em função do teor de umidade para uma faixa comum de umidade de 18,6 a $62,6 \%$ b.u.

A Figura 2 apresenta, também, uma curva média para a massa específica em função do teor de umidade, cujos pontos correspondem à massa específica média, para todas as variedades e graus de maturação, a cada teor de umidade. $O$ desvio-padrão médio, neste caso, é igual a $0,03 \mathrm{~g} \mathrm{~cm}^{-3}$. É interessante notar que, para cada ponto (mesmo teor de umidade) a diferença máxima entre a maior e a menor massa específica, independente da variedade e do grau de maturação, é de $0,11 \mathrm{~g} \mathrm{~cm}^{-3}$, ou seja, para uma incerteza de $0,1 \mathrm{~g} \mathrm{~cm}^{-3} \mathrm{e}$ para cada teor de umidade, o valor da massa específica é o mesmo para grãos de quaisquer variedades e grau de maturação.

O processo de determinação do teor de umidade do café é moroso; qualquer metodologia nova que reduzisse o tempo envolvido neste processo implicaria em um grande benefício e, se os níveis de umidade dos grãos nos experimentos fossem iguais, para cada combinação de variedade e grau de maturação, existiria a possibilidade de se ajustar uma única curva a todos os dados experimentais obtendo-se, assim, uma equação para massa específica real, em função do teor de umidade. $\mathrm{O}$ uso desta equação, na forma inversa, permitiria a determinação do teor de umidade em função da massa específica de uma amostra, que pode ser determinada rapidamente.

No caso dos dados apresentados neste trabalho, em que foram obtidos valores de massa específica para grãos de café a níveis diferentes de teor de umidade testou-se, para cada combinação de variedade e grau de maturação, uma outra forma de exploração dos dados. O processo, referenciado na Figura 2, consiste em usar a evidência de que, para cada teor de umidade, os valores da massa específica, com apenas uma casa decimal, são os mesmos para todas as variedades e graus de maturação.

Assim, usando-se as equações ajustadas para cada combinação de variedade de café e grau de maturação, obtevese uma faixa de valores para o teor de umidade correspondente a determinado valor de massa específica; essas faixas se encontram na Tabela 4 e esquematizadas na Figura 2; elas são para o intervalo de umidade, de 18,6 a 62,6\% b.u., conforme o ajuste das curvas. Experimentalmente, existem dados abaixo e acima dos limites; portanto, a primeira e a última faixas embutiriam, na prática, provavelmente, teores de umidade menores e maiores, respectivamente. Assim, se a massa específica real de uma amostra resultar em um valor de, por exemplo, $0,8 \mathrm{~g} \mathrm{~cm}^{-3}$, poder-se-á dizer que seu teor de umidade se encontra entre 19,9 e 31,4\% b.u., o que já é um indicativo rápido da sua umidade.

Tabela 4. Faixa de teor de umidade para uma amostra com a mesma massa específica

\begin{tabular}{cccc}
\hline Massa específica & \multicolumn{3}{c}{ Faixa de teor de umidade (\% b.u.) } \\
\cline { 2 - 4 } $\mathrm{g} \mathrm{cm}^{-3}$ & Inicial & Final & Comprimento \\
\hline 0,7 & 18,6 & 19,8 & 1,2 \\
0,8 & 19,9 & 31,4 & 11,5 \\
0,9 & 31,5 & 45,6 & 14,1 \\
1,0 & 45,7 & 62,6 & 16,9 \\
\hline
\end{tabular}

A Figura 3 apresenta, para fins de comparação, as curvas ajustadas para as massas específicas reais do café Catuaí e Timor, e de outros tipos de grãos, equações extraídas de Brusewitz

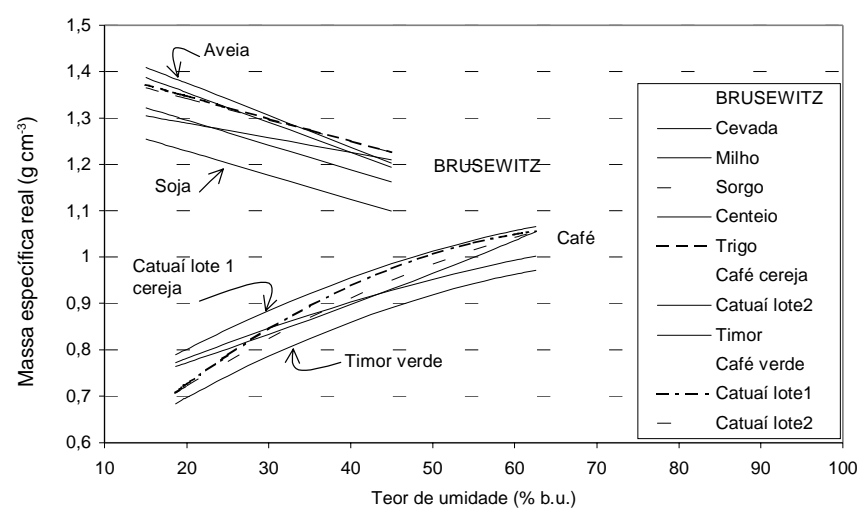

Figura 3. Massas específicas reais, provenientes das equações ajustadas, para grãos de café das variedades Catuaí e Timor e para outros grãos (extraído de Brusewitz, 1975) 
(1975). Pode-se observar, nesta figura, que os valores para a massa específica real do café são bem menores que aqueles para os outros grãos. O valor desta grandeza para café a $62,6 \%$ b.u. é aproximadamente igual àquele para soja a $45 \%$ b.u.; o comportamento da massa específica real do café é o inverso daquele para os outros grãos, pois enquanto para o café a massa específica cresce com o aumento de umidade do grão, para os outros ela decresce. Os dados experimentais e as curvas ajustadas para a massa específica real do café não apresentam qualquer tendência de alterar este comportamento.

\section{Massa específica aparente}

Os valores médios determinados para a massa específica aparente do café, Tabela 1, variaram de 391,3 a $606,6 \mathrm{~kg} \mathrm{~m}^{-3}$ e os desvios-padrão relativos a cada média variaram de maneira desuniforme, desde 1 até $13 \mathrm{~kg} \mathrm{~m}^{-3}$.

Observa-se, nos dados na Tabela 1, que existe, para cada variedade, tendência da massa específica aparente diminuir com o decréscimo no teor de umidade do produto, indicando que, ao se reduzir a umidade de uma amostra de grãos, a sua massa é reduzida mais rapidamente que o seu volume.

Observa-se, ainda, nessa tabela, para as variedades Catuaí (lote 1) e Timor, que os valores da massa específica aparente de grãos classificados, inicialmente, como cereja, tendem a ser maiores que para os classificados, de início, como verde.

$\mathrm{Na}$ Figura 4 podem ser visualizadas as curvas das equações ajustadas, cujos coeficientes se encontram na Tabela 2, para a massa específica aparente, em função do teor de umidade, de grãos de café das variedades Catuaí e Timor, para amostras contendo grãos verde e cereja e, também, os valores experimentais, média das três determinações.

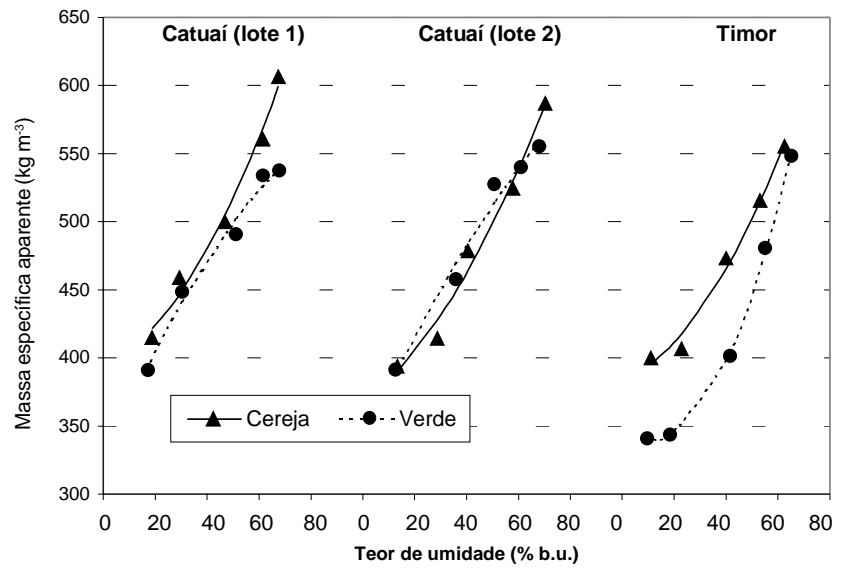

Figura 4. Massa específica aparente de café das variedades Catuaí e Timor, inicialmente classificado como cereja e verde, em função do teor de umidade. Curvas ajustadas e valores experimentais

Nota-se pequena diferença (Figura 4) do comportamento da massa específica aparente de grãos classificados inicialmente como cereja e verde, sendo mais acentuada para a variedade Timor. Se as equações ajustadas forem utilizadas usando-se um intervalo de umidade comum a todas as variedades e graus de maturação (18,6 a 62,6\% b.u.) verificar-se-á que, em média, as massas específicas aparentes (com uma casa decimal) de grãos inicialmente classificados como cereja são, para a variedade Catuaí, lotes 1 e 2, iguais aos classificados como verde e, para a variedade Timor, são 1,2 vezes superiores ao verde.
A Figura 5 apresenta valores provenientes das equações ajustadas, para as massas específicas dos grãos das duas variedades de café, classificados, de início, cereja e verde, para um intervalo comum de umidade (18,6 a 62,6 \% b.u.). Pode-se observar que os maiores valores são, praticamente, para grãos cereja da variedade Catuaí (lote 1).

Estes valores são, em média, para todos os teores de umidade, $11 \%$ superiores àqueles para a variedade Timor, verde, que apresentam os menores valores de massa específica aparente. Os valores da massa específica aparente para grãos da variedade Catuaí, classificados, de início, como cereja e verde, dos lotes 1 e 2, foram iguais, para uma casa decimal, indicando, portanto, não ter havido alterações relevantes no produto, devido à época de colheita (Figura 5).

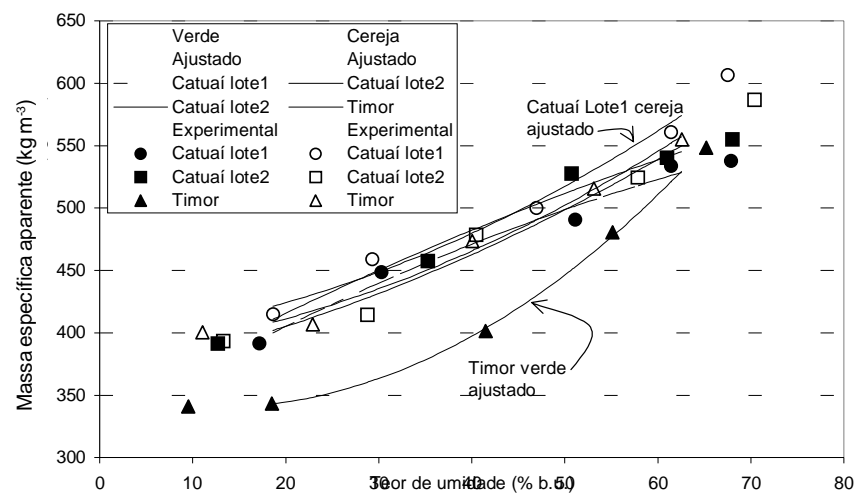

Figura 5. Massa específica aparente, proveniente das equações ajustadas de grãos de café das variedades Catuaí e Timor, inicialmente classificados como cereja e verde, em função do teor de umidade para uma faixa comum de umidade de 18,6 a $62,6 \%$ b.u.

A Figura 6 apresenta, para fins de comparação, as curvas ajustadas para as massas específicas aparentes do café Catuaí e Timor, e de outros tipos de grãos, equações extraídas de Brusewitz (1975). Pode-se observar, nesta figura, que os valores para a massa específica aparente do café são menores que aqueles para os outros grãos, exceto para a aveia. Os grãos de café comportam-se, em termos de massa específica aparente, de maneira diferente que a maioria dos grãos agrícolas, cuja massa específica aparente decresce com acréscimos no teor de umidade do produto até certo valor passando, a seguir, a crescer, exceto a soja e o sorgo, para os quais a massa específica aparente decresce durante todo o intervalo. A massa específica aparente

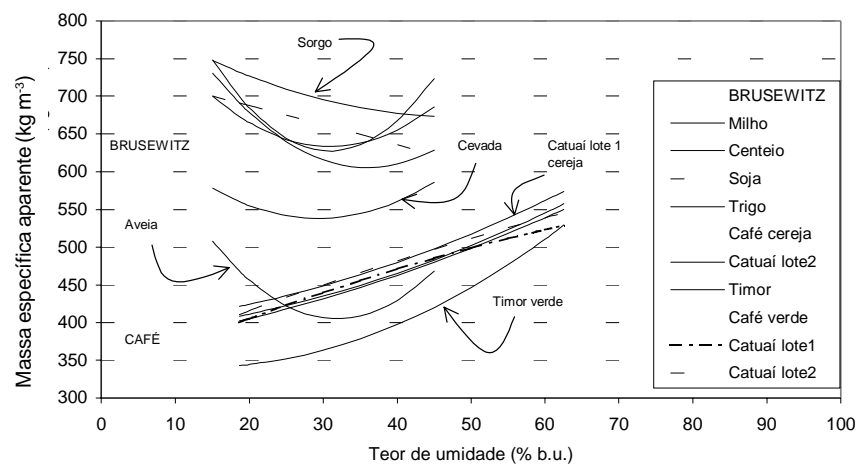

Figura 6. Massas específicas aparentes, provenientes das equações ajustadas para grãos de café das variedades Catuaí e Timor e para outros grãos (extraído de Brusewitz, 1975) 
de grãos de café cresce com aumento de umidade do grão e, ao se observar os dados experimentais e as curvas ajustadas para a massa específica aparente do café, não se nota qualquer tendência de alteração deste comportamento.

\section{Porosidade}

Na determinação da porosidade de uma amostra de grãos de café, introduziram-se na Eq (3) os dados experimentais relativos à massa específica aparente (originais) e à massa específica real (média para cada combinação de variedade, grau de maturação e teor de umidade). Os valores médios da porosidade, exibidos com os respectivos desvios-padrão na Tabela 1 , variaram de 38,8 a $53 \%$.

Na Figura 7 podem ser visualizadas as curvas das equações ajustadas, cujos coeficientes se encontram na Tabela 2, para a porosidade, em função do teor de umidade, e de amostras de café das variedades Catuaí e Timor, contendo grãos verde e cereja e, também, os valores experimentais, média das três determinações.

Nota-se, nesta figura, que a porosidade das amostras cresce com o teor de umidade dos grãos até determinado valor e, então, decresce; exceção se faz à variedade Catuaí lote 2, cereja, para a qual a porosidade parece pouco se alterar com o teor de umidade.

Para a variedade Timor, em quase todo o intervalo os valores da porosidade de amostras contendo grãos verdes foram superiores àqueles das amostras contendo grãos cereja, indicando uma provável diferença na porosidade de amostras que, antes do processo de secagem, continham grãos verde e cereja.

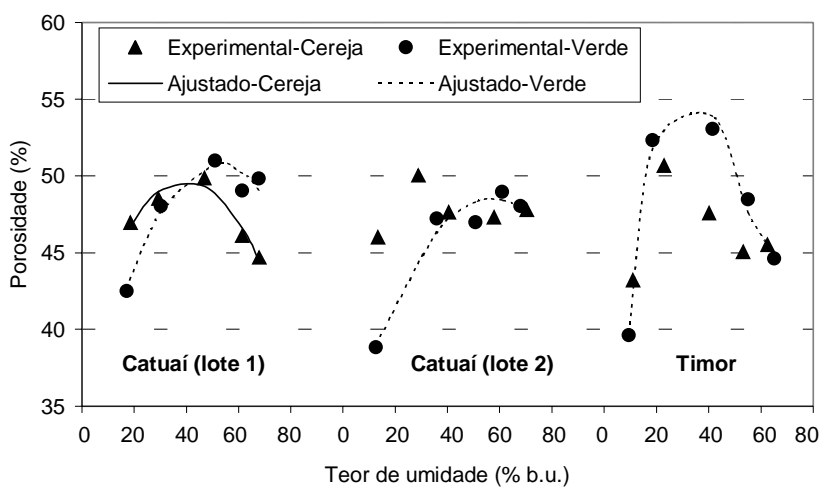

Figura 7. Porosidade de amostras de café Catuaí e Timor, inicialmente classificados como cereja e verde, em função do teor de umidade. Curvas ajustadas e valores experimentais

Se as equações ajustadas forem utilizadas em um intervalo de umidade comum a todas as variedades e graus de maturação (18,6 a $62,6 \%$ b.u.), Figura 8 , poder-se-á observar que para a variedade Catuaí, lote 1, a porosidade de amostras contendo grãos classificados inicialmente como cereja é, até a umidade de $40 \%$ b.u., em média, $4 \%$ maior que para aquelas contendo grão verde. A partir deste ponto, a porosidade de amostras contendo grãos verdes passa a ser $4 \%$ maior que a daquelas contendo grãos cereja. A diferença máxima entre os valores de porosidade para amostras contendo grãos cereja e verde foi de 3,8 .

Ao se comparar amostras de café da variedade Catuaí que continham, de início, grãos de café verde, observa-se que a porosidade do lote 1 é, em média 5,2\% maior que aquela para o lote 2. Deve-se observar que o desvio-padrão máximo entre as determinações de porosidade, para cada teor de umidade e variedade, foi igual a 1,7 e que, para o intervalo de umidade comum, foi igual a 1,0, o que indica tendência de o lote 1 diferir do lote 2 , em termos de porosidade.

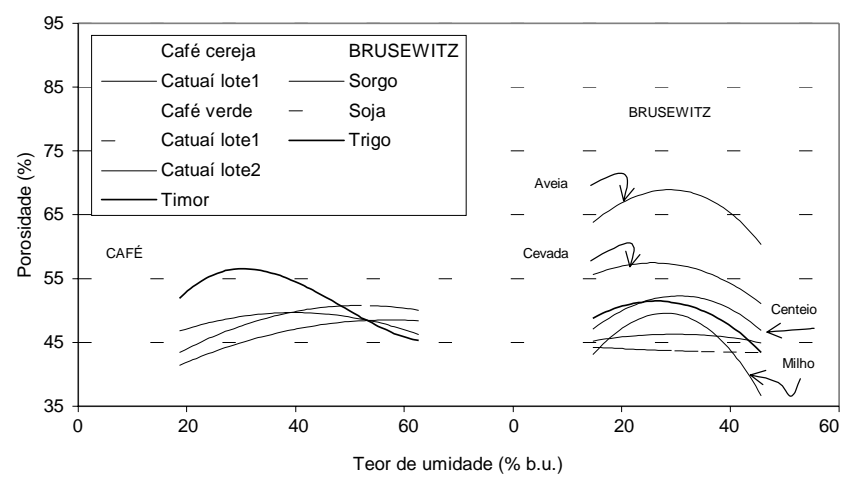

Figura 8. Porosidade proveniente das equações ajustadas para amostras de café das variedades Catuaí e Timor e para amostras de outros grãos (extraído de Brusewitz, 1975)

A Figura 8 apresenta, também, para fins de comparação, as curvas ajustadas para as porosidades de amostras de outros tipos de grãos, equações extraídas de Brusewitz (1975). Pode-se observar, nesta figura, que os valores para a porosidade do café encontram-se na mesma faixa daqueles para a maioria dos grãos, diferindo apenas para os da aveia. Observa-se, também, que o comportamento da porosidade de amostras de café é bastante similar ao dos outros grãos, em que as curvas ajustadas passam, em geral, por um máximo. É interessante notar que esse fato ocorre apesar do comportamento das massas específicas real e aparente das amostras de café diferir daquele para outros tipos de grãos.

\section{CONCLUSÕES}

1. A massa específica real do café, cuja variação foi de 0,565 a $1,124 \mathrm{~g} \mathrm{~cm}^{-3}$, é menor que a observada para a maioria dos grãos agrícolas; seu comportamento, em função do teor de umidade dos grãos, também difere daquele da maioria dos grãos agrícolas. Para acréscimo no teor de umidade, enquanto a massa específica dos últimos decresce, a do café aumenta.

2. Quando a massa específica real de grãos de café é determinada com uma incerteza de $0,1 \mathrm{~g} \mathrm{~cm}^{-3}$, seus valores, para dado teor de umidade, independem da variedade ou do grau de maturação, antes do processo de secagem.

3. A época de colheita do café da variedade Catuaí não produziu alterações relevantes nos valores das massas específicas real e aparente de seus grãos.

4. A massa específica aparente do café, que variou de 391,3 a $606,6 \mathrm{~kg} \mathrm{~m}^{-3}$, é menor que a apresentada pela maioria dos grãos agrícolas, sendo comparável à da aveia; seu comportamento, em função do teor de umidade dos grãos, difere da maioria dos outros grãos. Para acréscimo no teor de umidade, enquanto a massa específica desses últimos decresce, até determinado valor e, a seguir, cresce, a massa específica aparente do café decresce continuamente durante todo o intervalo de umidade investigado.

5. Os maiores valores de massa específica aparente foram, em geral, para o café da variedade Catuaí, $11 \%$ superiores àqueles encontrados para a variedade Timor, cujos grãos foram classificados, inicialmente, como verdes; esses últimos apresentaram os menores valores e diferiram de todos os outros; 
7. Para café da variedade Catuaí, os valores de massa específica aparente, para determinado teor de umidade, foram bastante próximos, ou seja, parecem independer do grau de maturação; já para a variedade Timor, a massa específica de grãos cereja foi, aproximadamente, $20 \%$ superior à dos grãos verdes.

8. Os valores de porosidade determinados para grãos de café, que variaram de 38,8 a 53,0\%, encontram-se na mesma faixa de valores de porosidade observada para a maioria dos grãos. $\mathrm{O}$ comportamento da porosidade, em função do teor de umidade, é similar ao dos outros grãos: cresce com a umidade do grão, até um valor máximo e, a seguir, decresce.

\section{REFERÊNCIAS BIBLIOGRÁFICAS}

BROOKER, D.B.; BAKKER-ARKEMA, F.W.; HALL, C.H. Drying and storage of grains and oilseeds. Westport: AVI, 1992. 450p.
BRUSEWITZ, G.H. Density of rewetted high moisture grains. Transactions of the ASAE, St. Joseph, v. 18, n. 5, p. 935-938, 1975.

HALL, G.E. Test-weight changes of shelled corn during drying. Transactions of the ASAE, St. Joseph, v. 15, n. 2, p. 320-323, 1972.

MOREIRA, S.M.C.; CHAVES, M.A.; OLIVEIRA, L.M. Comparação da eficiência de líquidos na determinação da massa específica aparente de grãos agrícolas. Revista Brasileira de Armazenamento, Viçosa, v. 9, n. 1 e 2, p. 22-24, 1984/85.

NELSON, S.O. Moisture-dependent kernel- and bulk-density relationships for wheat and corn. Transactions of the ASAE, St. Joseph, v. 23, n. 1, p. 139-143, 1980.

SRIVASTAVA, A.K.; GOERING, C.E.; ROHRBACH, R.P. Engineering principles of agricultural machines. St. Joseph, Michigan: American Society of Agricultural Engineers, 1993.601p. 